\title{
Effective Method of Microcapsules Production for Smart Fabrics
}

\author{
Luz Sánchez-Silva, Paula Sánchez and Juan F. Rodríguez \\ Department of Chemical Engineering/University of Castilla-La Mancha \\ Spain
}

\section{Introduction}

Nowadays, the attempts in the textile and clothing industry have moved towards more innovative and high quality products in order to differentiate themselves and be more competitive. The new demand for innovative textiles is increasingly oriented to match material innovation, new technologies and fashion. The new products are not only different for their lines, patterns and volumes but also for what they can do. Recently, microcapsules have been applied to many functional and technical textiles. Examples of this include fragrances, aromatic deodorants, cosmetics, insect repellents, antibiotics, polychromic, drug delivery for medical textiles and thermo-regulating systems. This kind of fabrics, that introduces new functionalities without affecting the look and feel of the textile, is commonly denominated as smart textiles.

Microencapsulated phase change materials (PCM) can be incorporated into textile structures to produce fabrics of enhanced thermal properties. A thermo-regulating fabric is an intelligent textile that has the property of offering suitable response to changes in external temperature changes or to external and environmental stimuli. The level of thermal comfort depends on the heat exchange between the human body and the environment that surrounds it.

Microcapsule production may be achieved by means of physical and chemical techniques. The use of some techniques has been limited to the high cost of processing, regulatory affairs, and the use of organic solvents, which are concern for health and the environment. In this way, a method based on a suspension like polymerization process for the encapsulation of phase change materials has been selected. This PCM encapsulation method is simply, inexpensive and technically easy.

Suspension like polymerization involves the dispersion of the monomer or monomers, mainly as a liquid in small droplets, into an agitated stabilizing medium consisting of water containing small amounts of suspension agents and without using aqueous phase inhibitors of secondary nucleation or modifiers. The initiator is dissolved in the monomer-PCM mixture and PCM material does not take part on the polymerization kinetic. In the proper conditions the polymer reacts mainly in the interface of the drop forming a shell around the PCM core since this interface is the only locus of polymerization. However, not all the recipes and conditions for suspension polymerization favour the formation of the polymer at the PCM/water interface all around the drop as desired and microparticles without complete phase separation into capsules are obtained. 
Well-known PCM are linear chain hydrocarbons known as paraffin waxes (or n-alkanes), hydrated salts, polyethylene glycols (PEGs), fatty acids and mixture or eutectics of organic and non-organic compounds. PCM materials absorb energy during the heating process as phase change takes place and release energy to the environment in the phase change range during a reverse cooling process.

The required properties for a phase change materials depend on their specific application in textile fields. A wide spectrum of phase change materials are available with different heat storage capacity and phase change temperature. Different types of commercial PCMs can be encapsulated by means of suspension polymerization process. Rubitherm ${ }^{\circledR}$ RT20, Rubitherm $^{\circledR}$ RT27, Rubitherm ${ }^{\circledR}$ RT31, Petrepar ${ }^{\circledR}$ n-C14 and Petrepar $^{\circledR}$ n-C-13 have demonstrate their capability to be encapsulated and their thermal abilities to absorb and release energy. Their physical and chemical properties make them very attractive for thermal storage.

Thermal properties, air permeability, moisture vapour permeability and moisture regain of materials also influence the heat balance of the body and, consequently, affect clothing comfort (Ren \& Ruckman, 2004). The incorporation of PCM microcapsules to textiles can affect other comfort-related properties and hand of the materials adversely, especially when the topical application of microcapsules results in drastic changes in the surface characteristics of materials. The extent of change in these properties depends on the loading amount of PCM microcapsules (Shin et al., 2005).

Several methods of incorporating PCM microcapsules into a fibrous structure have been developed. The microcapsules can be applied by stamping works, exhaustion dyeing, impregnation, spraying and coating or by direct incorporation in the fibre without highly modifying its touch and colour (Monllor et al., 2009; Dixit \& Goal, 2007; Rodrigues et al., 2009). In previous applications of PCM technology in the textile industry, for garments and home furnishing products, microencapsulated PCM were incorporated into acrylic fibers (Bryant \& Colvin, 1988) or polyurethane foams (Colvin \& Bryant, 1996) or were embedded into a coating compound and topically applied to a fabric (Bryant \& Colvin, 1994). Shin et al., (2005) incorporated melamine-formaldehyde microcapsules containing eicosane on polyester knit fabrics by means of a pad dry cure method with a polyurethane binder. Mengjin et al., (2008) developed a new kind of thermo-regulating fiber based on PVA and paraffin. Furthermore, Onder et al., (2008) studied the microencapsulation of three types of paraffin waxes by complex coacervation to improve thermal performances of woven fabrics. Recently, Koo et al. (2009) have attempted to demonstrate the application of PCM microcapsules on waterproof nylon fabrics and to enhance thermal insulation effect with ceramic materials $(\mathrm{SiC})$ by using a dual coating method.

Binders play a crucial role in microcapsule coating formulation for various textile materials, as they are required to fix microcapsules on textile supports permanently. To a large extend, binders determine the quality, durability and washability of textile materials with microencapsulated ingredients. Some of the most frequently used binders in textile are water-soluble polymers, such as starch and modified starches, carboxymethyl cellulose; synthetic latexes, such as styrene-butadiene, polyvinylacetate or acrylate latexes; and aminoaldehyde resins (Boh \& Knez, 2006).

In our previous work, the fixation of PCM microcapsules containing paraffin with a melting point around $40^{\circ} \mathrm{C}$, into a cotton textile substrate by means of a coating technique were carried out. Furthermore, the influence of different coating formulations and mass ratio of microcapsules to coating formulation were evaluated in order to obtain an adequate textile 
with thermo-regulating properties (Sánchez et al., 2010). The coating fabric with 35 wt.\% of microcapsules added related to commercial coating binder (WST SUPERMOR ${ }^{\circledR}$ ) showed a energy storage capacity of $7.6 \mathrm{~J} \mathrm{~g}^{-1}$, a high durability and an adequate stability after washing, rub fastness and ironing treatments. A difference of $8.8^{\circ} \mathrm{C}$ for $6 \mathrm{~s}$ was observed for textiles with thermo-regulating properties in comparison with a coated one without microcapsules. The different application areas of textiles with thermo-regulating properties imply the fixation to very different substrates. In this sense, there are few references in the literature studying the influence of the kind of textile on the fixation of microcapsules (Koo et al., 2009). In addition, the PCM microcapsules incorporation could degrade the original functionalities of the textile such as soft touch, vapor or moisture permeability and wearing comfort.

The aim of this work was to investigate the production of textiles with thermo-regulating properties by using PCM microcapsules and a coating technique. The influence of the type of used PCM on the heat capacity of microcapsules, the particle size distribution (PSD) and the microcapsules yield of each experiment was studied. On the other hand, different type of textile substrates depending on the field of their textile applications (apparel, blankets, insulation, protective clothing) were evaluated. Furthermore, a study of thermoregulatory effect of the coating fabrics produced was carried out using an infrared thermography camera. Thermal properties of textile samples were examined by Differential Scanning Calorimetry (DSC). Furthermore, Environmental Scanning Electron Microscopy (ESEM) and Optical Microscopy (OM) techniques were used to check the presence, surface distribution, preferred join position and to analyse the structure of microcapsules into the textile.

\section{Experimental}

\subsection{Microcapsules synthesis}

Styrene (99 wt.\%) of reagent grade (Merck Chemical) previously purified by washing with sodium hydroxide and dried with calcium chloride was used as the monomer. Benzoyl peroxide (97 wt.\%) was used as initiator (Fluka Chemical). PRS ${ }^{\circledR}$ paraffin wax, Rubitherm ${ }^{\circledR}$ RT20, Rubitherm ${ }^{\circledR}$ RT27, Rubitherm ${ }^{\circledR}$ RT31, Petrepar ${ }^{\circledR}$ n-C14 and Petrepar ${ }^{\circledR}$ n-C-13 were used as core materials. Polyvinylpyrrolidone (K30, Mw 40,000 gmol-1) of reagent grade (Fluka Chemical) was used as stabilizer and methanol to pour the samples. All these reagents were used as received. Water was purified by distillation followed by deionization using ion-exchange resins. Nitrogen was of high-purity grade $(99.999 \%)$.

A suspension like polymerization process was used for the microcapsules synthesis. A tubular type Shirasu porous glass membrane was used for a better control of microparticle size. Details of the synthesis process were previously described elsewhere (Sánchez et al., 2008b).

\subsection{Preparation of textiles with thermo-regulating properties}

Microcapsules were fixed into seven fabrics by means of a coating technique, using a motorized film applicator from Elcometer model 4340 according with ASTM D-823C (ASTM D-823-C, 1997). WST SUPERMOR ${ }^{\circledR}$ (supplied by Minerva Color Ltd.) were used as commercial coating binder. In a previous study (Sánchez et al., 2010), this binder was selected due to allow an efficient fixation of the PCM microcapsules on the fabrics. Every sample had $200 \mathrm{~mm}$ of wide and $290 \mathrm{~mm}$ of length due to requirements of the motorized film applicator. 
The coating formulation consisted of WST SUPERMOR ${ }^{\circledR}$ commercial binder and Rubitherm ${ }^{\circledR}$ RT31 microcapsules (35 wt. \% of the coating mixture).

The textile substrate was set on the motorized film applicator surface assuring the fabric with clips. In this study, the thickness selection of the coating layer was $0.1 \mathrm{~mm}$ to obtain a high thermal storage. The position of the motorized film applicator and the selection thickness was carried out manually. A dragging speed of $5 \mathrm{~mm} \mathrm{~s}^{-1}$ was chosen to allow a homogeneous coating along the film applicator.

Finally, the coated fabric was cured at $95^{\circ} \mathrm{C}$ for 11 minutes.

\subsection{Characterization}

\subsubsection{Differential Scanning Calorimetry (DSC)}

Measurements of melting point and latent heat storage capacities of different materials were performed in a differential scanning calorimetry model DSC Q100 of TA Instruments equipped with a refrigerated cooling system and nitrogen as the purge gas. Measurements were carried out in the temperature range from $-30^{\circ} \mathrm{C}$ to $80^{\circ} \mathrm{C}$ with heating and cooling rate of $10{ }^{\circ} \mathrm{Cmin}^{-1}$.

Various samples of each experiment were analyzed at least three times and the average value was recorded. DSC analyses of coating textiles from random areas were done.

Furthermore, the encapsulation ratio of the different PCM in the microcapsule was calculated with the following equation based on enthalpy values:

$$
\% \mathrm{PCM} \text { content by weight }=(\Delta \mathrm{Hm} / \Delta \mathrm{Hpcm}) \times 100 \%
$$

where $\Delta \mathrm{Hm}$ is the enthalpy for the analysed microcapsules $\left(\mathrm{Jg}^{-1}\right)$ and $\Delta \mathrm{Hpcm}$ is the enthalpy of pure PCM.

In order to determine the thermal stability of the reversible phenomena of phase change, the coated textiles were subjected to repeated cycles of melting and crystallization.

\subsubsection{Environmental scanning electron microscopy (ESEM)}

ESEM was used to analyze the morphological structure of the microcapsules and the fixation and integrity of PCM microcapsules into the coating textile substrates. Textile samples were observed by using XL30 (LFD) ESEM with a wolfram filament operating at a working potential of $20 \mathrm{kV}$.

\subsubsection{Calculation of number-average diameter and volume-average diameter} Particle size and particle size distribution (PSD) of microcapsules were determined on a Malvern Mastersizer Hydro 2000 SM light scattering apparatus with dilute dispersions of the particles in methanol.

\subsubsection{Infrared thermography}

The temperature distributions of the coated textiles with thermo-regulating properties were evaluated by means of an infrared and visible camera Fluke Ti25. This dispositive allows to obtain thermal and visual images in the range of temperatures from $-20^{\circ} \mathrm{C}$ to $250^{\circ} \mathrm{C}$ with a precision of $\pm 2{ }^{\circ} \mathrm{C}$. The screen was observed from a distance of $30 \mathrm{~cm}$ at $24^{\circ} \mathrm{C}$. Images were downloaded using Fluke SmartViewTM software for analysis. The coated fabrics were preheated at $60^{\circ} \mathrm{C}$, time considered as zero, and then cooled to room temperature. 
Thermal human comfort in summer conditions was tested, recording images from $25^{\circ} \mathrm{C}$ to outside temperature $\left(35^{\circ} \mathrm{C}\right)$, comparing a reference textile with a prototype textile with thermo-regulating properties in contact with the body (shoulders in this specific case).

\section{Results}

\subsection{Microencapsulation of different type of phase change materials (PCM)}

The required properties for a phase change materials depend on their specific application in textile fields. A wide spectrum of phase change material is available with different heat storage capacity and phase change temperature. In this study different type of commercial PCM were assayed in order to know what PCM materials are suitable to be encapsulated by means of suspension polymerization. Thus, Rubitherm ${ }^{\circledR}$ RT20, Rubitherm ${ }^{\circledR}$ RT27, Rubitherm ${ }^{\circledR}$ RT31, Petrepar ${ }^{\circledR}$ n-C14 and Petrepar $^{\circledR}$ n-C-13 were assayed due to their physical and chemical properties are very attractive for thermal storage (Table 1). All of them are saturated hydrocarbons

\begin{tabular}{|c|c|c|c|c|}
\hline PCM & $\begin{array}{l}\text { Molecular } \\
\text { weight } \\
\left(\text { gmol-1) }^{-1}\right)\end{array}$ & $\begin{array}{c}\text { Latent heat } \\
\text { of fusion } \\
\left(\mathrm{Jg}^{-1}\right)\end{array}$ & $\begin{array}{c}\text { Melting } \\
\text { temperature } \\
\left({ }^{\circ} \mathrm{C}\right)\end{array}$ & $\begin{array}{c}\text { Viscosity } \\
\left(\mathrm{mm}^{2} \mathrm{~s}^{-1}\right) \\
\text { at } 98^{\circ} \mathrm{C}\end{array}$ \\
\hline PRS ${ }^{\circledR}$ paraffin wax & $168-240$ & 206.8 & $40-45$ & 2.43 \\
\hline Rubitherm ${ }^{\circledR}$ RT31 & 268 & 199.3 & 31 & 2.07 \\
\hline Rubitherm ${ }^{\circledR}$ RT27 & 258 & 214.6 & 28 & 1.64 \\
\hline Rubitherm ${ }^{\circledR}$ RT20 & 244 & 177.7 & 22 & 1.52 \\
\hline Petrepar $^{\circledR}$ n-C14 & 198.4 & 225.0 & $3-7$ & 0.99 \\
\hline Petrepar $^{\circledR}$ n-C13 & 184.4 & 134.4 & $(-7)-(-5)$ & 0.88 \\
\hline
\end{tabular}

Table 1. Properties of different types of PCMs investigated

Figure 1 shows the particle size distributions (PSDs) in volume (Figure 1a) and in number (Figure $1 \mathrm{~b}$ ) of microcapsules obtained after the polymerization process using these PCM materials. It can be seen from Figure 1a that Petrepar ${ }^{\circledR}$ n-C14 and n-C13 exhibit bimodal PSDs with particles sizes smaller than $115 \mu \mathrm{m}$. However, PRS® paraffin wax, Rubitherm ${ }^{\circledR}$ RT31, RT27 and RT20 shows unimodal PSDs ranging in the interval between 149 to $251 \mu \mathrm{m}$. In all experiments a big difference between the average particle size in volume and in number was observed due to the heterogeneous sizes of obtained microcapsules. This behaviour was reported in previous works (Sánchez et al., 2007; Sánchez et al., 2008a; Sánchez et al., 2008b).

Table 2 reports average diameters $\left(\mathrm{dp}_{0.5}\right)$ in volume and in number, storage energy capacities and amount of PCM encapsulated of microcapsules produced using different PCMs. The mean diameter in number of the microcapsules increases as described: Rubitherm ${ }^{\circledR}$ RT27>PRS ${ }^{\circledR}$ paraffin wax $>$ Rubitherm ${ }^{\circledR}$ RT31> Petrepar $^{\circledR}$ C-14>Petrepar ${ }^{\circledR}$ C-13>Rubitherm ${ }^{\circledR}$ RT20. However, the average diameter in volume increases in the following way: Rubitherm ${ }^{\circledR}$ RT27 $>$ Rubitherm ${ }^{\circledR}$ RT31 $>$ Rubitherm ${ }^{\circledR}$ RT20 $>$ PRS ${ }^{\circledR}$ paraffin wax $>$ Petrepar ${ }^{\circledR}$ $\mathrm{n}-\mathrm{C} 14>$ Petrepar $^{\circledR} \mathrm{n}-\mathrm{C} 13$. Therefore, the average diameter of the microcapsules depends on 
phase change materials encapsulated. For PRS ${ }^{\circledR}$ paraffin wax, Petrepar ${ }^{\circledR}$ C-14 and Petrepar ${ }^{\circledR}$ $\mathrm{C}-13$, the average diameter of microcapsules enlarged with increasing the viscosity. This fact could be due to the polymerization system is subject to nonnegliglible effects of the viscosity ratio (dispersed phase/continuous phase viscosity). According to Hamielec \& Tobita, (1992) in suspension polymerization an increase of the forming droplets viscosity and the density difference between the phases results in a tendency towards settling. However, this trend was not observed for Rubitherm materials.

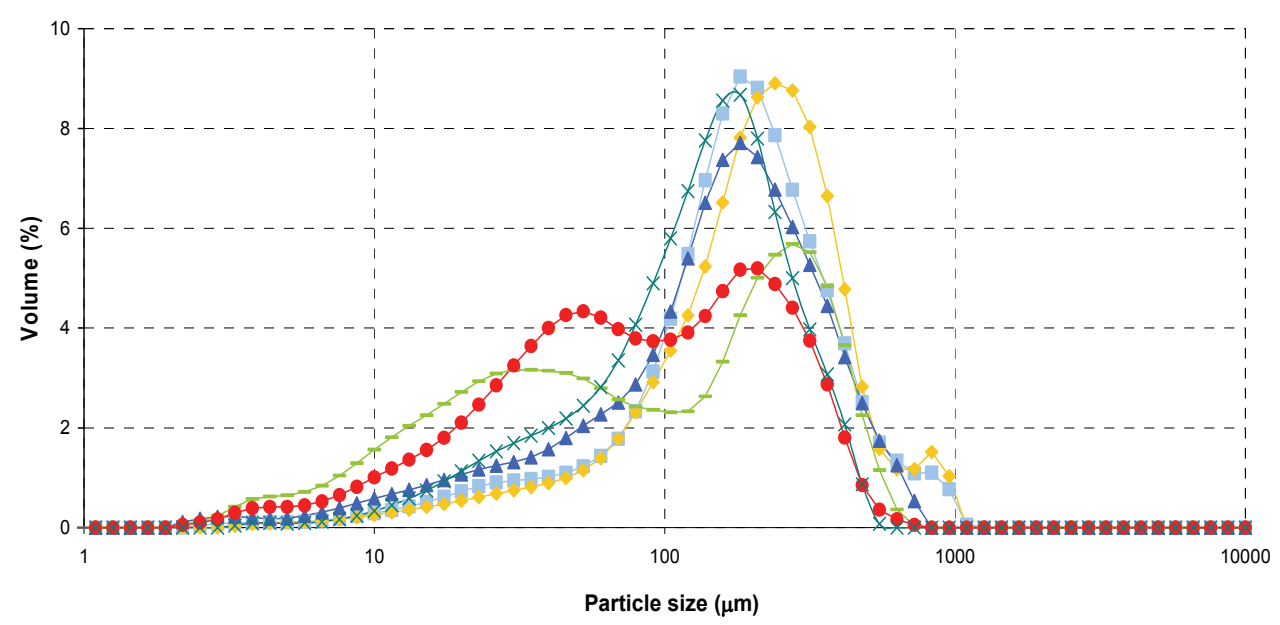

(a)

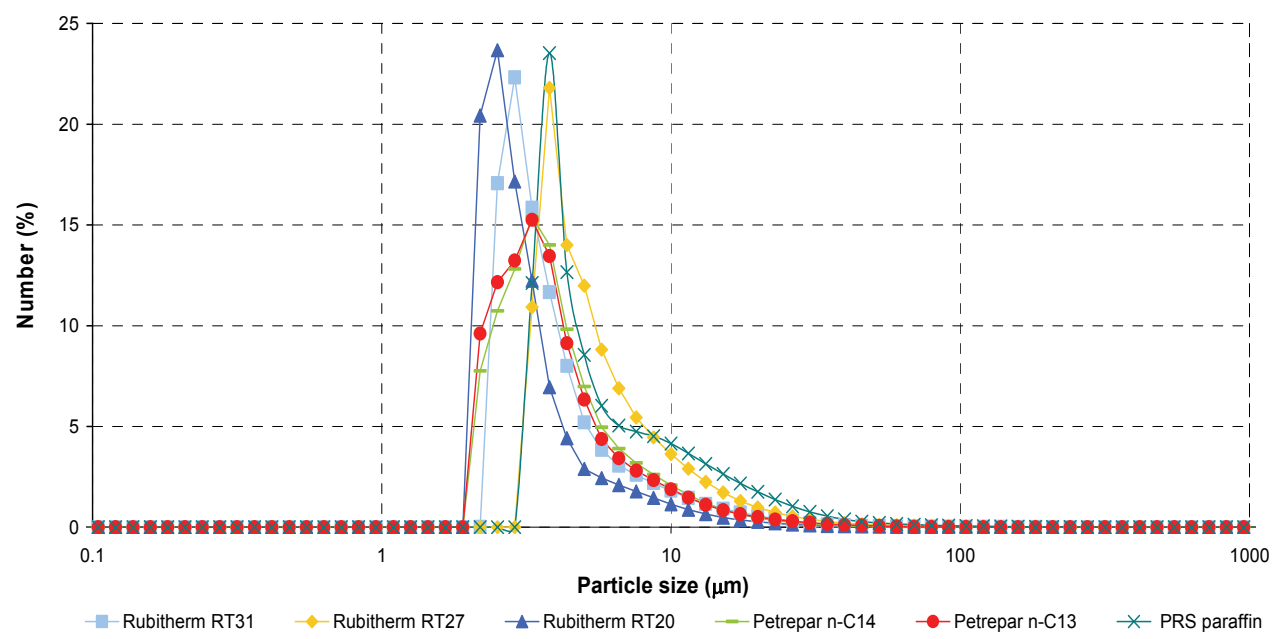

(b)

Fig. 1. Particle size distribution for microcapsules obtained using different PCM: (a) in volume and (b) in number 


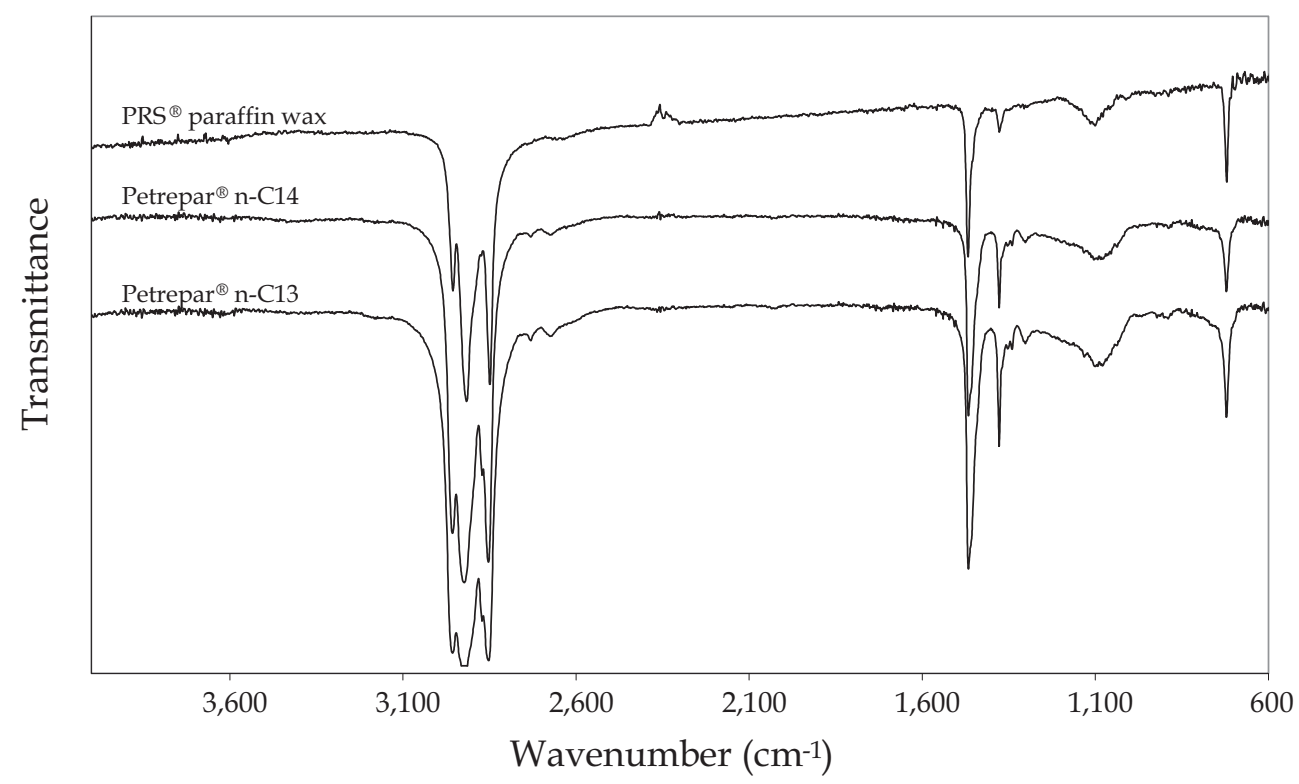

(a)

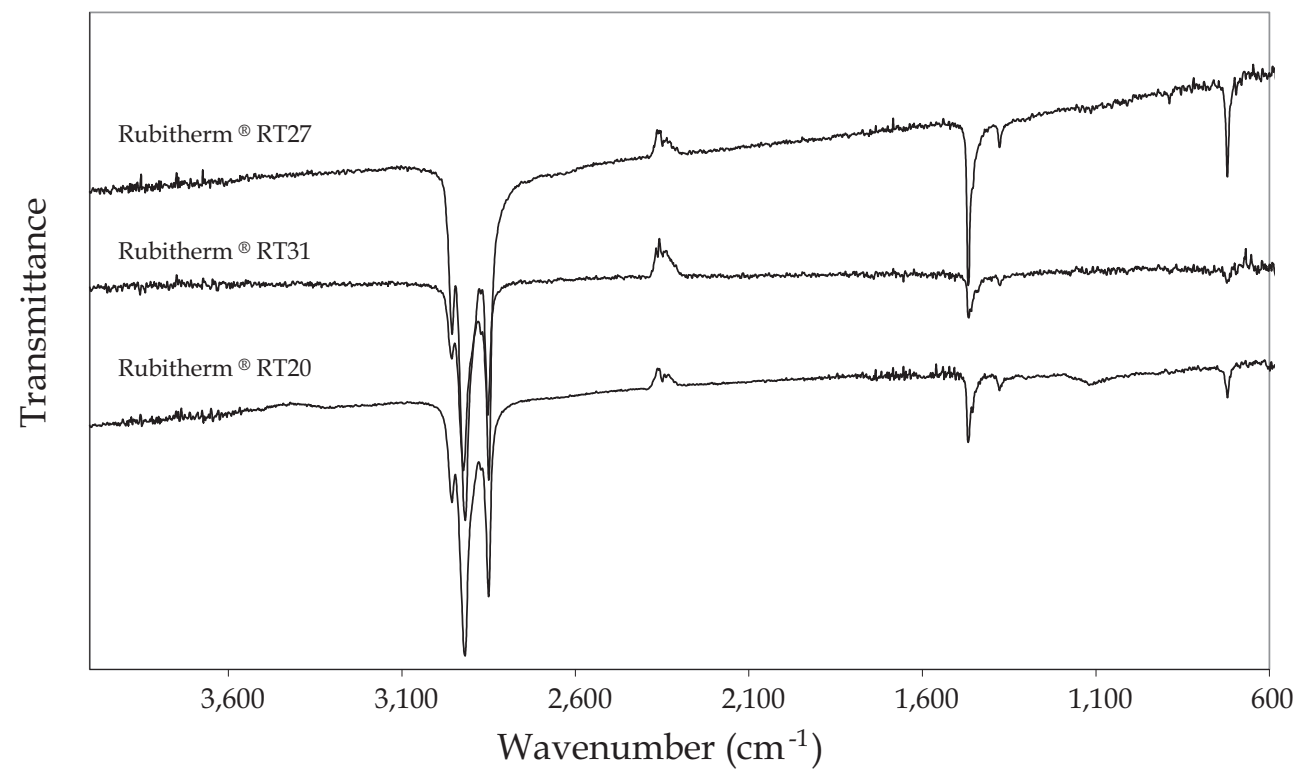

(b)

Fig. 2. FTIR spectra of: (a) PRS ${ }^{\circledR}$ paraffin wax, Petrepar ${ }^{\circledR}$ C-14 and Petrepar $^{\circledR}$ C-13 and (b) Rubitherm ${ }^{\circledR}$ RT27, Rubitherm ${ }^{\circledR}$ RT31 and Rubitherm ${ }^{\circledR}$ RT20 
This behaviour can be attributed to chemical nature of these commercial PCMs according to the FTIR spectra of the different PCMs obtained (Figure 2). In the spectrums of the PRS ${ }^{\circledR}$ paraffin wax, Petrepar ${ }^{\circledR}$ C-14 and Petrepar ${ }^{\circledR}$ C-13 materials (Figure 2b), in contrast to that of the Rubitherm products (Figure 2a), medium intensity bands in the $980-1,240 \mathrm{~cm}^{-1}$ were observed. These bands indicate the presence of ethyl and propyl groups branches. Therefore, PRS ${ }^{\circledR}$ paraffin wax, Petrepar ${ }^{\circledR}$ C-14 and Petrepar ${ }^{\circledR}$ C-13 are not straight chain alkanes.

\begin{tabular}{|c|c|c|c|c|}
\hline PCM & $\begin{array}{l}\mathrm{dpv}_{0.5} \\
(\mu \mathrm{m})^{1}\end{array}$ & $\begin{array}{l}\mathrm{dpn}_{0.5} \\
(\mu \mathrm{m})^{2}\end{array}$ & $\begin{array}{l}\text { Thermal storage energy } \\
\qquad\left(\mathrm{Jg}^{-1}\right)\end{array}$ & $\begin{array}{l}\text { PCM encapsulated } \\
\text { (wt. \%) }\end{array}$ \\
\hline PRS $^{\circledR}$ paraffin wax & 149.0 & 4.53 & 104.7 & 50.1 \\
\hline Rubitherm ${ }^{\circledR}$ RT31 & 203.9 & 4.01 & 98.7 & 49.5 \\
\hline Rubitherm ${ }^{\circledR}$ RT27 & 250.9 & 6.02 & 100.2 & 46.7 \\
\hline Rubitherm ${ }^{\circledR}$ RT20 & 180.1 & 2.86 & 68.3 & 38.5 \\
\hline Petrepar $^{\circledR}$ n-C14 & 110.7 & 3.97 & 79.0 & 35.1 \\
\hline Petrepar $^{\circledR}$ n-C13 & 93.9 & 3.83 & 58.6 & 43.6 \\
\hline
\end{tabular}

${ }^{1} \mathrm{dpv} 0.5$ represents $50 \%$ microcapsule particles whose mean volumetric diameter is less than this value. ${ }^{2} \mathrm{dpn}_{0.5}$ represents $50 \%$ microcapsule particles whose mean numeric diameter is less than this value.

Table 2. Average diameters and thermal properties of microcapsules containing different PCM

DSC measurements confirm that all PCMs studied have been successfully encapsulated inside the polystyrene microcapsules (Table 2). PRS ${ }^{\circledR}$ paraffin wax, Rubitherm ${ }^{\circledR}$ RT27 and Rubitherm ${ }^{\circledR}$ RT31 allow to obtain microcapsules with energy storage capacities higher than $98 \mathrm{Jg}^{-1}$ and approximately $50 \mathrm{wt}$.\% of encapsulation efficiency.

Figure 3 shows the environmental scanning electron microscopy (ESEM) micrographs of microcapsules prepared with different phase change materials. It can be seen from Figure 3 that microcapsules prepared with PRS ${ }^{\circledR}$ paraffin wax, Petrepar ${ }^{\circledR}$ C-14 and $\operatorname{Petrepar}^{\circledR}$ C-13 and Rubitherm ${ }^{\circledR}$ RT27 and Rubitherm ${ }^{\circledR}$ RT31 are regularly spherical shape and smooth surface. However, the particles obtained with Rubitherm ${ }^{\circledR}$ RT20 have are irregular with rough surface, which can be attribute to the polarity of this product (Sánchez et al., 2007).

Although microcapsules containing PRS ${ }^{\circledR}$ paraffin wax, Rubitherm ${ }^{\circledR}$ RT27 and Rubitherm ${ }^{\circledR}$ RT31 have similar average thermal storage energies and regular spherical microcapsules with smooth surface. The most convenient melting temperature for an effective utilization of this kind of materials in textiles field was obtained using Rubitherm ${ }^{\circledR}$ RT31. Obviously, its phase change temperature $\left(31^{\circ} \mathrm{C}\right)$ is comfortable for the human body, and a higher efficiency of encapsulation $(49.5 \%)$ than the others.

\subsection{Influence of the kind of textile substrate on the production of smart fabric}

Seven fabrics substrates for different textile applications using Rubitherm ${ }^{\circledR}$ RT31 as core material were used. Their description and properties are shown in Table 3. Samples were named $A$ to $G$, according to the textile substrates employed. 

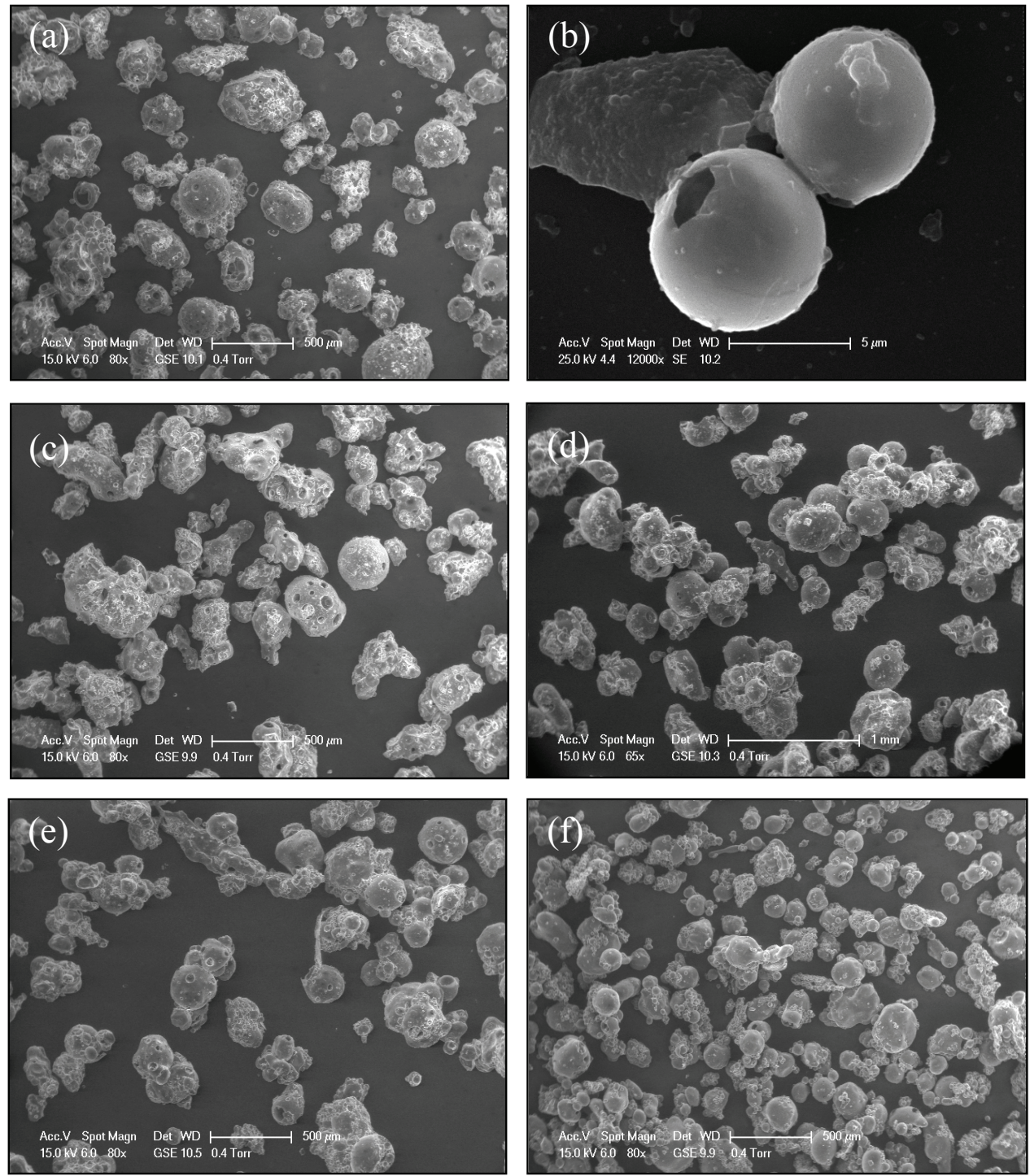

Fig. 3. ESEM micrographs of microcapsules containing: (a) Petrepar ${ }^{\circledR}$ C-13, (b) Petrepar $^{\circledR}$ C-14, (c) Rubitherm ${ }^{\circledR}$ RT20, (d) Rubitherm ${ }^{\circledR}$ RT27, (e) Rubitherm ${ }^{\circledR}$ RT31 and (f) PRS ${ }^{\circledR}$ paraffin wax

Thermal performance of different coated textiles with thermo-regulating properties with 35 wt. \% of PCM microcapsules as a function of the kind of textile substrate was evaluated by DSC analyses (Figure 4). It can be seen that all treated textile substrates allows to obtain thermo-regulating properties with acceptable latent heat storage capacities. The same result was observed by other authors (Salaün et al., 2010; Izzo Renzi et al., 2010). On the other 
hand, no significant differences on the phase change transition temperature of coated samples and the Rubitherm ${ }^{\circledR}$ RT31 microcapsules were observed. It was found that the melting transition points in the coated fabrics from A to G changed 0.72, 0.01, 0.13, 0.37, 0.13, -0.35 and $0.01{ }^{\circ} \mathrm{C}$, respectively. This indicated that the kind of textile substrate have not significant effect on the microcapsules melting effect. In this sense, Koo et al., (2009) observed changes up to $0.58^{\circ} \mathrm{C}$ by using a wet coating method.

\begin{tabular}{|c|c|c|c|c|}
\hline Sample & Composition & $\begin{array}{l}\text { Area } \\
\text { Weight } \\
\left(\mathrm{gm}^{-2}\right)\end{array}$ & $\begin{array}{l}\text { Thickness } \\
\text { (mm) }\end{array}$ & Uses \\
\hline A & $\begin{array}{l}\text { 82\% Polyester } \\
18 \% \text { Polyurethane }\end{array}$ & 296 & 1.50 & $\begin{array}{l}\text { Soft-Shell fabric with an } \\
\text { intermediate polyurethane } \\
\text { membrane for cold protection }\end{array}$ \\
\hline B & $\begin{array}{c}\text { 11\% Elastane } \\
35 \% \text { Polyamide } \\
54 \% \text { Polyester } \\
\end{array}$ & 270 & 1.34 & $\begin{array}{l}\text { Soft-Shell fabric with an } \\
\text { intermediate polyurethane } \\
\text { membrane for cold protection }\end{array}$ \\
\hline $\mathrm{C}$ & 100\% Polyamide & 202 & 0.48 & Green fabric for military uses \\
\hline $\mathrm{D}$ & $\begin{array}{l}100 \% \text { Polyester } \\
\text { coating with } \\
100 \% \text { PVC }\end{array}$ & 121 & 0.27 & $\begin{array}{l}\text { Yellow fabric for garments of } \\
\text { high visibility }\end{array}$ \\
\hline $\mathrm{E}$ & $\begin{array}{l}40 \% \text { Polyester } \\
60 \% \text { Cotton }\end{array}$ & 185 & 0.35 & $\begin{array}{l}\text { Openwork fabric in blue tone for } \\
\text { medical garments uses }\end{array}$ \\
\hline $\mathrm{F}$ & 100\% Polyamide & 328 & 0.61 & $\begin{array}{l}\text { Military printed fabric for } \\
\text { military uses }\end{array}$ \\
\hline G & $100 \%$ Cotton & 158 & 0.30 & $\begin{array}{c}\text { Fabric used for upholstery, } \\
\text { sheets, curtains and garments }\end{array}$ \\
\hline
\end{tabular}

Table 3. Textile substrates characterization and their textile uses

In our previous paper, textile substrate G (100\% cotton) was used to obtain the textiles with thermo-regulating properties (Sánchez et al., 2010). In the present work the employed experimental conditions were the same except for the thickness of the coating layer. A thermal storage capacity of $14.4 \mathrm{Jg}^{-1}$ was achieved using cotton textile substrate and a coating thickness of $0.1 \mathrm{~mm}$. Comparing this result with the value of $7.6 \mathrm{Jg}^{-1}$ obtained in the previous work with $0.01 \mathrm{~mm}$ of thickness, it is observed that the latent heat storage capacity of the treated fabric increased as the thickness of the coating layer increased.

Table 4 summarizes the latent heat storage capacity, the necessary time to decrease the temperature of coated textiles from 33 to $25^{\circ} \mathrm{C}$, the latent heat accumulated in $1 \mathrm{~m}^{2}$ of fabric substrate associated with each sample and the amount of PCM microcapsules added on each textile substrate. There are not important differences in the latent heat storage capacity and the amount of retained PCM microcapsules depending on the kind of used substrate textile. Coated textiles $\mathrm{A}$ and $\mathrm{B}$ exhibit the highest latent heat and a long thermoregulatory effect, due to the soft shell characteristics and the large thickness of these fabrics that allow to accommodate a high amount of PCM microcapsules and improve the resistance of heat transfer, respectively. Sample D with $16.3 \mathrm{Jg}^{-1}$ shows a short time of the heat release, this may be related to the small thickness of the used textile substrate $(0.27 \mathrm{~mm})$. For samples $\mathrm{E}$ 
and G the latent heat storage capacity, the amount of PCM microcapsules added on the textiles and the thickness of these textiles are similar, thus the duration of the thermal buffer effect was quite similar. Furthermore, the lowest latent heat storage capacity for samples having polyamide as textile substrate (samples $\mathrm{F}$ and $\mathrm{C}$ ) suggests that this composition does not allow the incorporation of a large amount of PCM microcapsules into the fabric. Nevertheless, small differences of latent heat storage capacity were obtained. According to these results, the heat transfer through fabric depends on the quantity of PCM microcapsules added on the coating binder but also the textile composition and structure. Consequently, numerous factors must be considered in the evaluation of the heat transfer properties of fabrics (Koo et al., 2009).

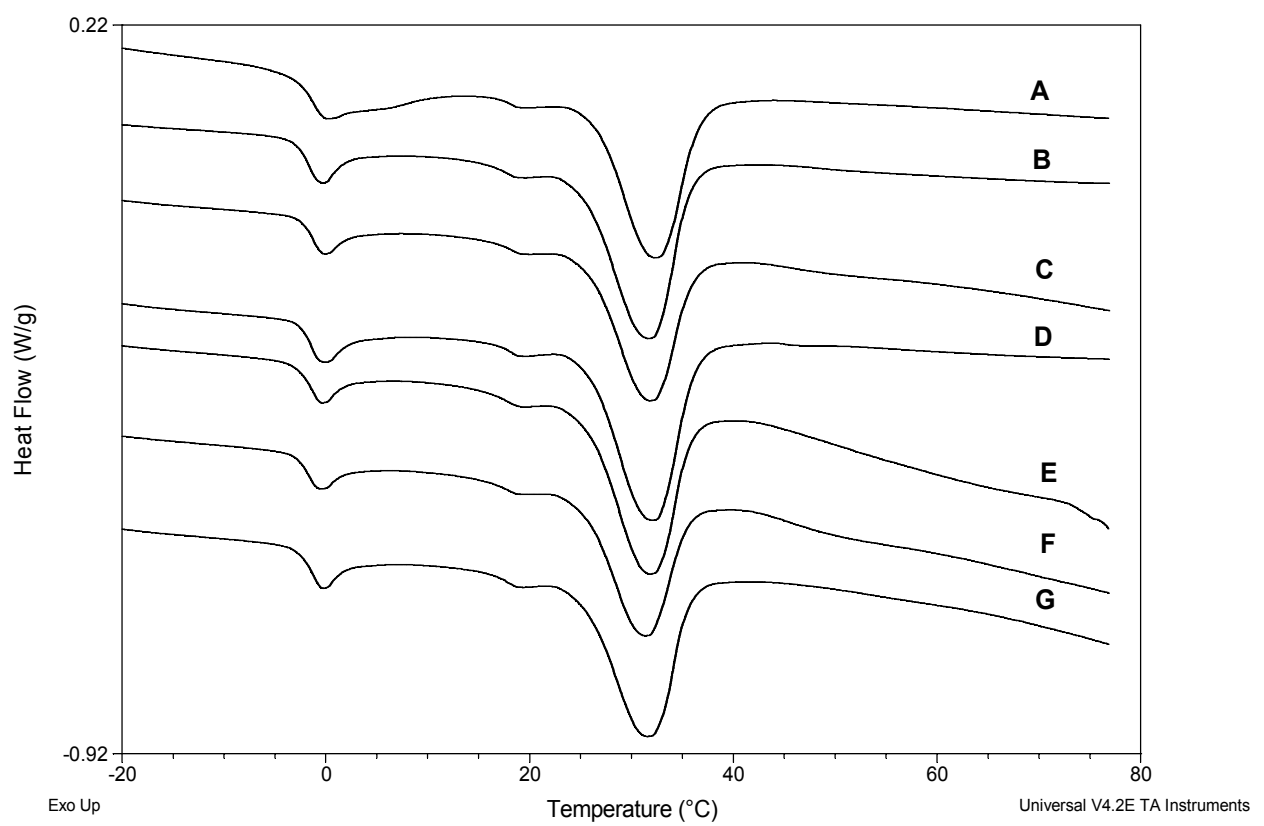

Fig. 4. DSC thermograms of the different coated textiles with $35 \mathrm{wt} . \%$ of microcapsules containing Rubitherm ${ }^{\circledR}$ RT31

Reliability tests to study the thermal performance of a textile with thermo-regulating properties (sample A) during thermal cycling were carried out using DSC analysis (Figure 5). It can be observed that the latent heat storage of the sample does not change when heating/cooling cycle is repeated (less than $2 \%$ of latent heat variation). Furthermore, melting and freezing transition points of the coated fabrics shift to higher temperature than microcapsules containing Rubitherm ${ }^{\circledR}$ RT31. This fact could be attributed to the influence of the polymeric binder on the thermal response of textile (Salaün et al., 2010).

Therefore, these results demonstrated that textile substrates with different characteristics and applications are suitable for application of the microcapsules by means of a coating method. Similar results of latent heat storage capacity using natural leather and $40 \mathrm{wt} . \%$ of PCM microcapsules were obtained by Izzo Renzi et al., (2010). 


\begin{tabular}{|c|c|c|c|c|}
\hline Sample & $\Delta H\left(J^{-1}\right)$ & $\begin{array}{l}\text { Duration of } \\
\text { the heat } \\
\text { release from } \\
33 \text { to } 25^{\circ} \mathrm{C}(\mathrm{s})\end{array}$ & $\begin{array}{c}\text { Latent heat } \\
\text { accumulated in } 1 \\
\text { m }^{2} \text { of fabric } \\
\text { substrate } \\
\left(\mathbf{k J m}^{-2}\right)\end{array}$ & $\begin{array}{c}\text { PCM } \\
\text { microcapsules } \\
\text { added on the } \\
\text { textile } \\
\text { (wt. } \%)\end{array}$ \\
\hline A & 19.4 & 79 & 5.7 & 25.6 \\
\hline B & 18.1 & 62 & 4.9 & 23.9 \\
\hline $\mathrm{C}$ & 13.5 & 65 & 2.7 & 17.8 \\
\hline $\mathrm{D}$ & 16.3 & 28 & 4.4 & 21.5 \\
\hline E & 14.3 & 42 & 2.6 & 18.9 \\
\hline $\mathrm{F}$ & 11.1 & 67 & 3.6 & 14.7 \\
\hline G & 14.4 & 48 & 2.3 & 19.0 \\
\hline
\end{tabular}

Table 4. Thermal properties of the thermo-regulating textiles

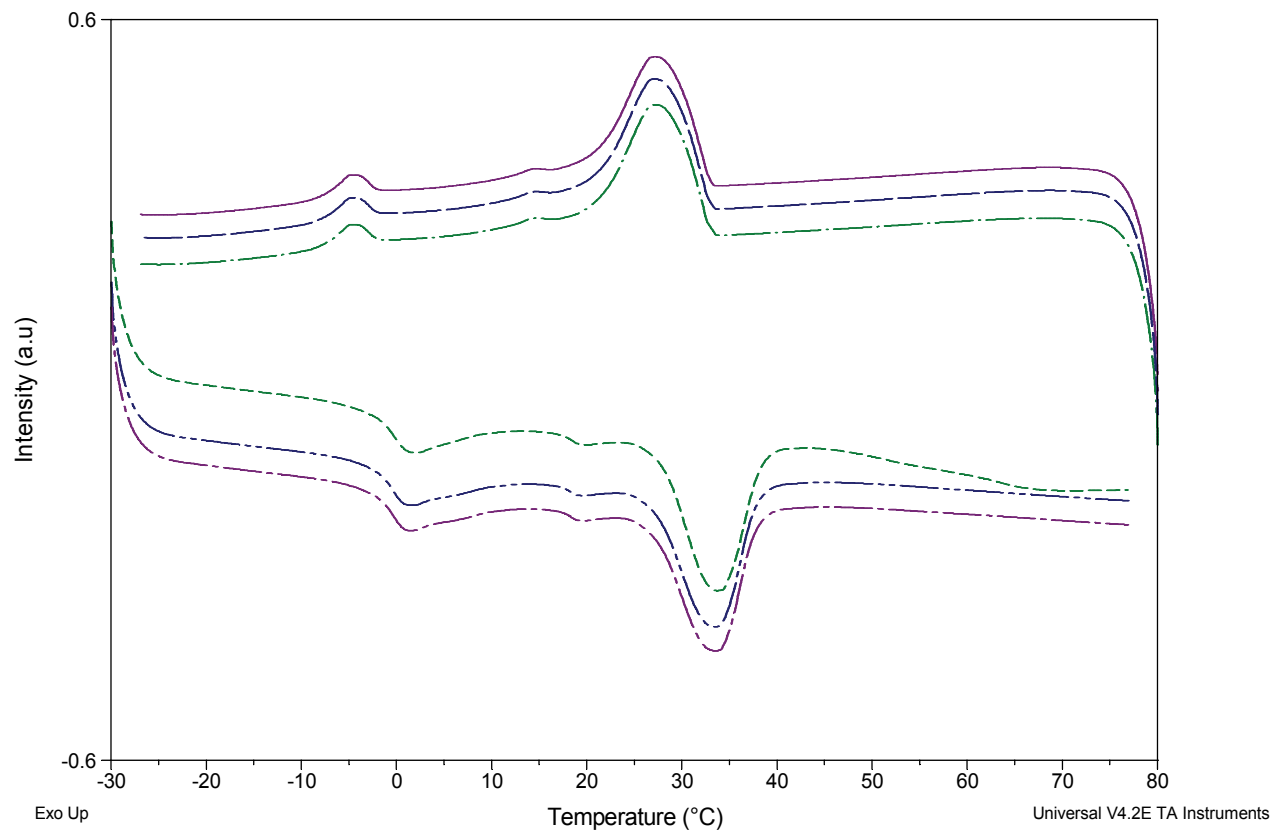

Fig. 5. DSC curves of a textile with thermo-regulating properties (sample A), triple scan

Figure 6 shows ESEM micrographs of the surface and the cross-sectional morphology of a representatively sample (coated textile A) in which PCM microcapsules were used as the thermal insulation material. It can be seen, the successful fixation between textile substrate and the microcapsules containing Rubitherm ${ }^{\circledR}$ RT31. The PCM microcapsules in the treated 
samples were mainly located at the spaces between fibers and the fiber surface. As shown in Figure $6 \mathrm{~b}$, the textile substrate $\mathrm{A}$ is remarkable thick leads to add a large amount of PCM microcapsules on the textile substrate according to DSC analysis obtained.
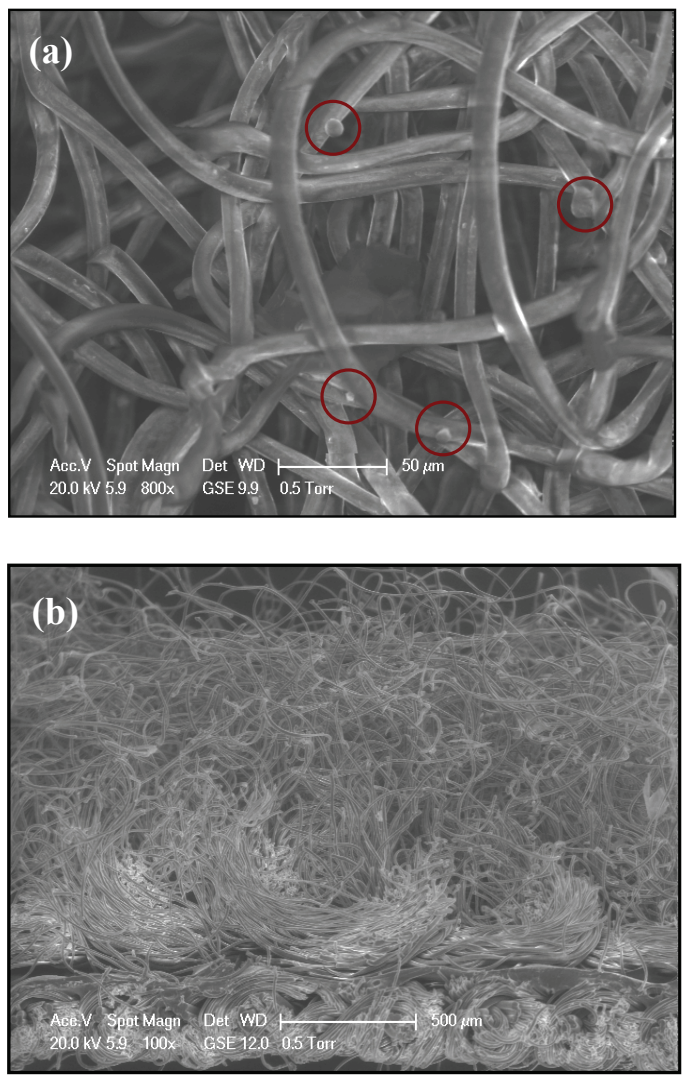

Fig. 6. ESEM micrographs of a thermo-regulating textile (sample A): (a) surface and (b) cross section

During the last years several testing methods have been developed for measuring the temperature-regulating ability of PCM in fabrics (Bryant \& Colvin, 1994; Mengjin et al., 2008; Onder et al., 2008; Koo et al., 2009). In this work, the efficiency of the active thermal insulation effect of the textiles with incorporated microcapsules has been evaluated using thermal vision camera. Figure 7 shows a comparison of the maxima temperature reached on the surface temperature distribution for the seven samples with the time. In this study, the coated textiles with and without PCM microcapsules were cooled from $60^{\circ} \mathrm{C}$ to room temperature.

In all the cases, Rubitherm ${ }^{\circledR}$ RT31 buffer effect is observed. Therefore, during the cooling process there is a temperature range when the temperature of coated textile with PCM microcapsules is higher than the non-coated one. This indicates that the stored energy of PCM is transferred to the environment in the phase change range during the reverse cooling 

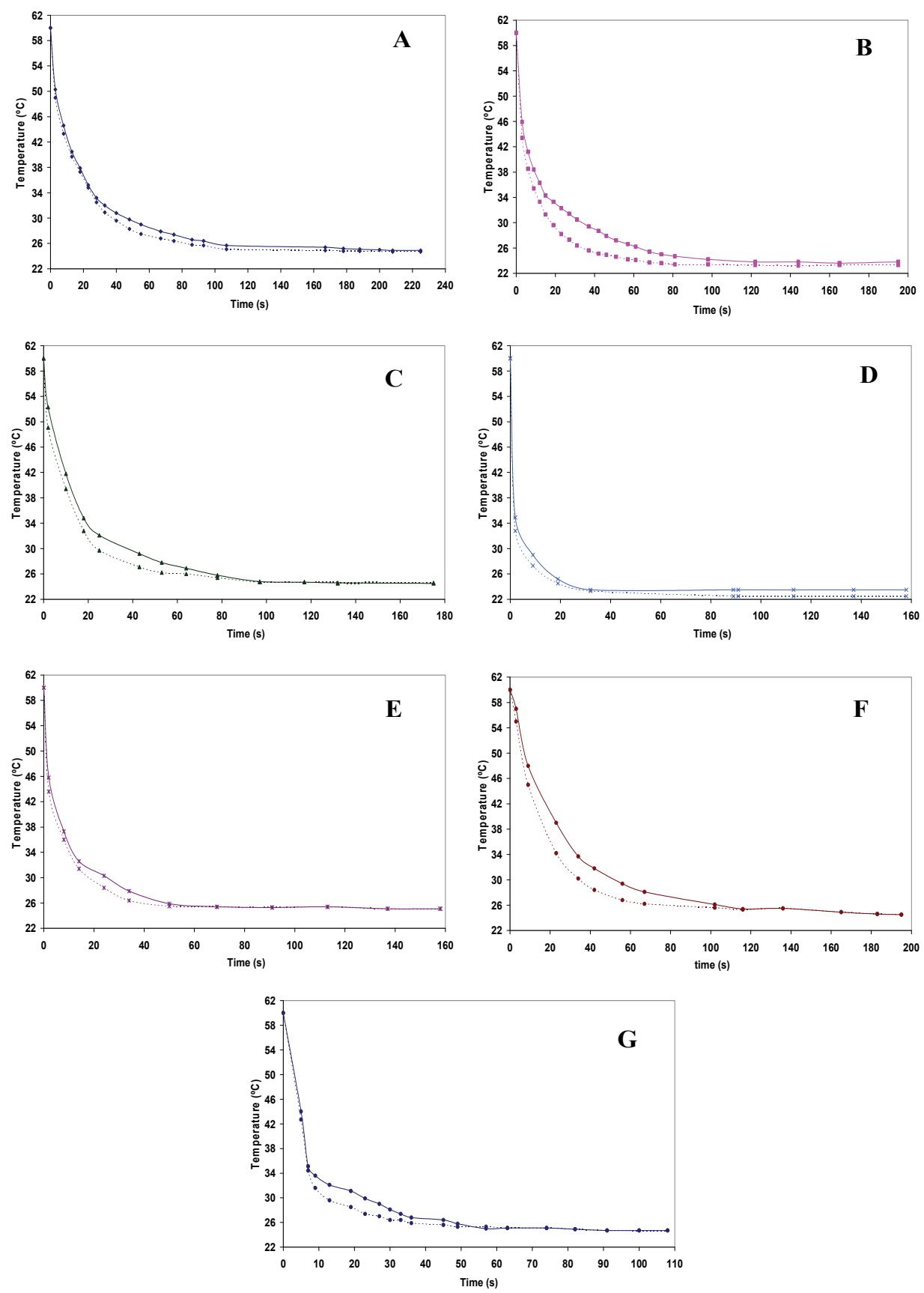

Fig. 7. Temperature distribution as a function of time for different coated textiles by thermal vision camera: ----- Textile without PCM microcapsules — Textile with PCM microcapsules 
process (Salaün et al., 2010). As it was previously mentioned, coated textile D exhibits the highest rate of temperature decrease and samples A and B have a significant effect on the thermal insulation.

With the aim to test the thermal comfort in summer conditions, the effect of a reference textile and a prototype of a textile with thermo-regulating properties in contact with the body (shoulders in this specific case) was visualized by IR thermography images (Figure 8). The zero time was taken when the individual went out to the building, from $25{ }^{\circ} \mathrm{C}$ (inside temperature) to $35^{\circ} \mathrm{C}$ (outside temperature).
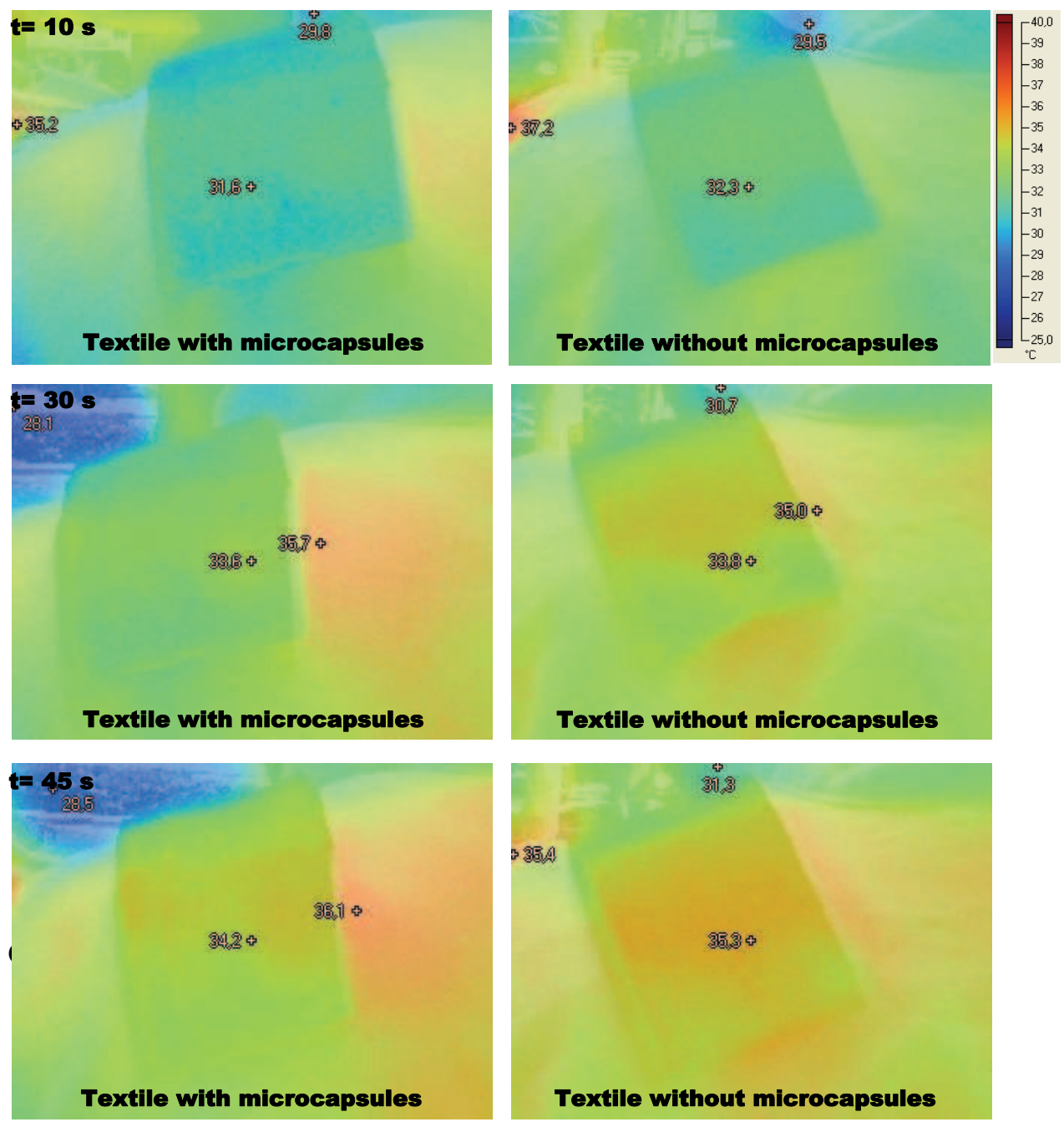

Fig. 8. Infrared camera images of coated textile A with and without PCM microcapsules at different times 
Thermal imagines show that textiles with thermo-regulating properties undergoes a heating effect less marked than the textile without PCM microcapsules, as a consequence of the melting process of encapsulated Rubitherm ${ }^{\circledR}$ RT31. Thermoregulatory effect observed for textile with PCM microcapsules with respect to the normal fabric was $1,0.9,0.8$ and $0.7{ }^{\circ} \mathrm{C}$ after 10, 30, 45 and $75 \mathrm{~s}$.

Concluding, the thermal performance of textiles with thermo-regulating properties depends on the energy storage capacity, PCM microcapsules content, textile substrate structure and the correspondence between the phase change temperature and the application temperature range. Consequently, thermal effects can be improved according to the final application request using an appropriate combination of all these parameters.

\section{Conclusion}

A method based on a suspension free radical polymerization process has been used for the encapsulation. Different phase change materials (PRS ${ }^{\circledR}$ paraffin wax, Petrepar ${ }^{\circledR}$ C-14 and Petrepar $^{\circledR}$ C-13 and Rubitherm ${ }^{\circledR}$ RT27 and Rubitherm ${ }^{\circledR}$ RT31) can be encapsulated by this method and form a core-shell structure. Although microcapsules containing PRS ${ }^{\circledR}$ paraffin wax, Rubitherm ${ }^{\circledR}$ RT27 and Rubitherm ${ }^{\circledR}$ RT31 have similar average thermal storage energies and regular spherical microcapsules with smooth surface. The most convenient melting temperature for an effective utilization of this kind of materials in textiles field was obtained using Rubitherm ${ }^{\circledR}$ RT31. Its phase change temperature $\left(31^{\circ} \mathrm{C}\right)$ is comfortable for the human body and it has a higher efficiency of encapsulation (49.5\%) than the others.

Fabrics with thermo-regulating properties had heat storage capacities of 11.1-19.4 Jg-1, which depended on the textile substrate. The DSC and the thermal temperature distribution analyses indicated that all the coated textiles with $35 \mathrm{wt}$. \% of microcapsules showed a high latent heat storage capacities and significant thermoregulatory effect. Furthermore, DSC curves demonstrated that the thermal energy storage of the textiles with thermo-regulating properties does not change when heating/cooling cycle was repeated. A thermoregulatory effect in contact with the body of $0.9^{\circ} \mathrm{C}$ after $45 \mathrm{~s}$ was observed by means of IR thermography images.

\section{Acknowledgment}

Financial support from ASINTEC S.A. and Ref. PBC08-0243-1458 from Consejería de Ciencia y Tecnología (JCCM) are gratefully acknowledged.

\section{References}

ASTM D 823-C. (1997). Standard practices for producing films of uniform thickness of paint, varnish, and related products on test panels

Boh, B. \& Knez, E. (2006). Microencapsulation of essential oils and phase change materials for applications in textile products, Indian Journal of Fibre and Textile Research, Vol.31, pp.72-82, ISSN 0971-0426

Bryant, Y.G. \& Colvin, D.P. (1988). Fiber with reversible enhanced thermal storage properties and fabric made therefrom, US Patent 4,756,958 
Bryant, Y.G. \& Colvin, D.P. (1994). Fabric with reversible enhanced thermal properties, US Patent 5,366,807

Colvin, D.P. \& Bryant, Y.G. (1996). Thermally enhanced foam insulation, US Patent 5,637,389

Dixit, S. \& Goel, A. (2007). Microencapsulation in textile processing: an overview, Asian Textile of Journal, Vol.16, pp. 83-86, ISSN 1819-3358

Hamielec, A.E. \& Tobita, H. (2003). Ullmann's Encyclopedia of Industrial Chemistry (Weinheim: WILEY-VCH).

Izzo Renzi, A.; Carfagna, C. \& Persico, P. (2010). Thermoregulated natural leather using phase change materials: An example of bioinsipiration, Applied Thermal Engineering, Vol.30, pp.1369-1376, ISSN 1359-4311

Koo, K.; Choe, J. \& Park, Y. (2009). The application of PCMMcs and SiC by commercially direct dual-complex coating on textile polymer, Applied Surface Science, Vol.255, pp.8313-8318, ISSN 0169-4332

Monllor, P.; Sánchez, L.; Cases, F. \& Bonet, M.A. (2009). Thermal behaviour of microencapsulated fragrances on cotton fabrics, Textile Research Journal, Vol. 79, pp. 365-380., ISSN 0040-5175

Mengjin, J.; Xiaoqing, S.; Jianjun, X. \& Guangdou, Y. (2008). Preparation of a new thermal regulating fiber based on PVA and paraffin, Solar Energy Materials \& Solar Cells Solar, Vol.92, pp. 1657-1660, ISSN 0927-0248

Onder, E.; Sarier, N. \& Cimen, E. (2008). Encapsulation of phase change materials by complex coacervation to improve thermal performances of woven fabric, Thermochimica Acta, Vol.467, pp. 63-72, ISSN 0040-6031

Pause, B. (2003). Nonwoven protective garments with thermo-regulating properties, Journal of Industrial Textiles, Vol.33, No.2, pp. 93-99, ISSN 1528-0837

Ren, Y.J. \& Ruckman, J.E. (2004). Condensation in Three-layer Waterproof Breathable Fabrics for Clothing, International Journal of Clothing Science and Technology, Vol.16, No.3, pp. 335-347, ISSN 0955-6222

Rodrigues, S.N.; Martins, I.M.; Fernandes, I.P.; Gomes, P.B.; Mata, V.G.; Barreiro, M.F. \& Rodrigues, A.E. (2009). Microencapsulated perfumes for textile application, Chemical Engineering Journal, Vol.149, pp. 463-472, ISSN 1385-8947

Salaün, F.; Devaux, E.; Bourbigot, S. \& Rumeau, P. (2010). Thermoregulating response of cotton fabric containing microencapsulated phase change materials, Thermochimica Acta. Vol. 506, No.1-2, pp. 82-93, ISSN 0040-6031

Sánchez, L.; Lacasa, E.; Carmona, M.; Rodríguez, J.F. \& Sánchez, P. (2008b). Applying an experimental design to improve the characteristics of microcapsules containing PCMs for fabric use, Industrial \& Engineering Chemistry Research, Vol.47, pp.97839790, ISSN 1520-5045

Sánchez, L.; Sánchez, P.; Carmona, M.; de Lucas, A. \& Rodríguez, J.F. (2008a). Influence of operation conditions on the microencapsulation of PCMs by means of suspensionlike polymerization. Colloid and Polymer Science, Vol.286, No.8-9, pp.1019-1027, ISSN 0303-402X

Sánchez, L.; Sánchez, P.; De Lucas, A.; Carmona, M. \& Rodríguez, J.F. (2007). Microencapsulation of PCMs with a polystyrene shell. Colloid and Polymer Science, Vol.285, No.12, pp.1377-1385, ISSN 0303-402X 
Sánchez, P.; Sánchez-Fernández, M.V.; Romero, A. ; Rodríguez, J.F. \& Sánchez-Silva, L. (2010). Development of thermo-regulating textiles using paraffin wax microcapsules, Thermochimica Acta, Vol.498, pp.16-21, ISSN 0040-6031

Shin, Y. ; Yoo, D.I. \& Son, K. (2005). Development of Thermoregulating Textile Materials with Microencapsulated Phase Change Materials (PCM). IV. Performance Properties and Hand of fabrics treated with PCM microcapsules, Journal of Applied Polymer Science, Vol.97, pp.910-915, ISSN 0021-8995 


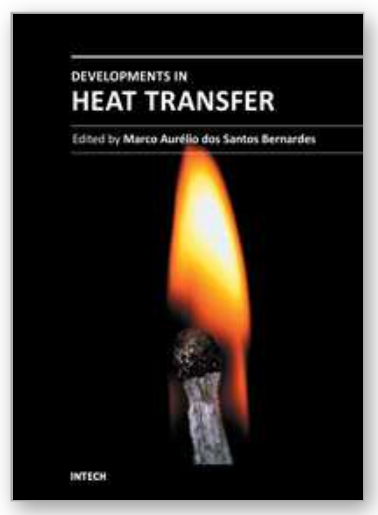

\author{
Developments in Heat Transfer \\ Edited by Dr. Marco Aurelio Dos Santos Bernardes
}

ISBN 978-953-307-569-3

Hard cover, 688 pages

Publisher InTech

Published online 15, September, 2011

Published in print edition September, 2011

This book comprises heat transfer fundamental concepts and modes (specifically conduction, convection and radiation), bioheat, entransy theory development, micro heat transfer, high temperature applications, turbulent shear flows, mass transfer, heat pipes, design optimization, medical therapies, fiber-optics, heat transfer in surfactant solutions, landmine detection, heat exchangers, radiant floor, packed bed thermal storage systems, inverse space marching method, heat transfer in short slot ducts, freezing an drying mechanisms, variable property effects in heat transfer, heat transfer in electronics and process industries, fission-track thermochronology, combustion, heat transfer in liquid metal flows, human comfort in underground mining, heat transfer on electrical discharge machining and mixing convection. The experimental and theoretical investigations, assessment and enhancement techniques illustrated here aspire to be useful for many researchers, scientists, engineers and graduate students.

\title{
How to reference
}

In order to correctly reference this scholarly work, feel free to copy and paste the following:

Luz Sánchez-Silva, Paula Sánchez and Juan F. Rodríguez (2011). Effective Method of Microcapsules Production for Smart Fabrics, Developments in Heat Transfer, Dr. Marco Aurelio Dos Santos Bernardes (Ed.), ISBN: 978-953-307-569-3, InTech, Available from: http://www.intechopen.com/books/developments-in-heattransfer/effective-method-of-microcapsules-production-for-smart-fabrics

\section{INTECH}

open science | open minds

\section{InTech Europe}

University Campus STeP Ri

Slavka Krautzeka 83/A

51000 Rijeka, Croatia

Phone: +385 (51) 770447

Fax: +385 (51) 686166

www.intechopen.com

\section{InTech China}

Unit 405, Office Block, Hotel Equatorial Shanghai

No.65, Yan An Road (West), Shanghai, 200040, China

中国上海市延安西路65号上海国际贵都大饭店办公楼 405 单元

Phone: +86-21-62489820

Fax: +86-21-62489821 
(C) 2011 The Author(s). Licensee IntechOpen. This chapter is distributed under the terms of the Creative Commons Attribution-NonCommercialShareAlike-3.0 License, which permits use, distribution and reproduction for non-commercial purposes, provided the original is properly cited and derivative works building on this content are distributed under the same license. 